\title{
Underdetermination, Assemblage Studies and Educational Technology: Rethinking Causality and Re-Energising Politics
}

\section{Carlo Perrotta ()}

Faculty of Education, Monash University, Australia

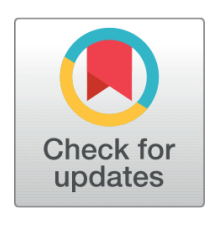

Received 2020-08-10

Revised 2020-09-24

Accepted 2020-12-05

Published 2021-01-15

\section{Corresponding Author}

Carlo Perrotta,

carlo.perrotta@monash.edu

Faculty of Education, Monash University, 29 Ancora Imparo

Way, Clayton VIC 3800

(Australia)

DOI https://doi.org/10.7821/ naer.2021.1.638

Pages: 43-56

Distributed under

Creative Commons CC BY 4.0

Copyright: (C) The Author(s)

\section{ABSTRACT}

This article examines underdetermination as a key theoretical assumption in an emerging body of educational research. Underdetermination is described as a broad philosophical position that assumes that social, scientific and technological phenomena cannot be reduced to linear relationships between antecedents and consequences, for instance through the canonical progression from scientific hypotheses to experimentation and then empirical truths. Rather, phenomena are underdetermined by constellations of social and material influences that make the choice of univocal explanations problematic. The principle of underdetermination is implicit in a recent strand of educational research that critiques orthodox interpretations of scientific practices, innovation processes and policy dynamics, recasting them as social, material and political "assemblages". In the article, I analyse the philosophical and epistemological tenets of underdetermination, in order to clarify its nature as a "first principle" in this emerging body of research. By doing so, the article brings into view a broader theoretical debate that has great bearing on future research efforts. The article critically considers the continued theoretical relevance of underdetermination, whilst acknowledging critical arguments mounted against it, namely ontological relativism and political weakness. Some supplementing theoretical ideas are explored in the conclusion.

Keywords THEORY, UNDERDETERMINATION, ASSEMBLAGE STUDIES, EDUCATION TECHNOLOGY, SCIENCE AND TECHNOLOGY STUDIES (STS)

\section{INTRODUCTION}

Our relationship with science and technology has historically been shaped by an assumption of causality. According to this assumption, scientific discoveries and technological innovations have observable impacts on individual and social outcomes, enabling us to satisfy needs and wants and, ultimately, to pursue truth. This view is inherently persuasive because based on a rationalistic (in many ways common-sensical) epistemology, often supported by the precise languages of engineering and mathematics. To say that this epistemology

\section{OPEN ACCESS}


is "deterministic" is not to question the very foundations of science and technology, but to highlight the risks of an uncritical and ideological commitment to them. In its most extreme manifestations, determinism leads to the notion that for every problem or challenge we may have as individuals and as societies, there is -or there could be- a technological fix: a solution to a narrowly defined problem which will act in a linear fashion according to a chain of causality. From a policy perspective, constructing science and technology as objective solutions (i.e. as "truth") places them in a sphere separate from the rest of other human and social matters, and thus elevates them by virtue of their functional value ("what works"). As a result, they are artificially insulated from scrutiny and can be easily co-opted by antidemocratic agendas where "facts" cannot be challenged on ethical or cultural grounds.

It is hardly controversial to claim that epistemological determinism played a considerable part in the birth and subsequent development of educational technology as an area of economic activity, scholarship and policy. This "ed-tech determinism" assumes that there are observable causal relations between computers on the one side and cognitive and behavioural outcomes on the other. Whether as instruments in the service of rational decision making (Zhao \& Frank, 2003), enhancers of learning and pedagogy (Luckin, 2010), or "toxic" artefacts begetting addiction and distraction (Jacobsen \& Forste, 2011), digital technologies in education have been seldom interrogated in non-deterministic ways. Back in the early 2010s, calls were made for educational technology scholarship to pursue research questions along social scientific lines, taking into account complex sociological and socio-psychological factors beyond the narrow study of cause-effect relations (Selwyn, 2010). While it would be unfair -and inaccurate- to suggest that no progress has been made, a critical observer in 2021 could be forgiven for thinking that the determining power previously ascribed to physical artefacts (computers, electronic whiteboards, smartphones and tablets) has not disappeared but simply pivoted towards complex data-based systems and their promises of personalisation and automation. What matters most, however, is that while research on educational technology may be showing more nuance and complexity, the hegemonic policy discourse is still overly preoccupied with "what works", where "what works" is equated with utopian ideals of political neutrality and objectivity.

There are, however, reasons to remain hopeful, at least as far as academic scholarship is concerned. Indeed, it could be argued that a novel mindset -let us call it "assemblage mindset"- gained popularity in some education research circles over the past decade. In this more critical perspective, technological and scientific facts are no longer causes of individual or social outcomes (good or bad), but the results of multiple influences operating within constellations of artefacts, practices and discourses, acting and being enacted in idiosyncratic ways. This position tries to upend the deterministic assumptions described above by bringing critically minded scholars into contact with the relational and political nature of knowledge. In this sense, "what works" is always political because it valorises one version of truth over another.

The current interest in digital infrastructures and platforms for data analysis and prediction reflects a similar attempt to account for the heterogeneity of technologies in the ambit of "educational assemblages", conceptualised as ensembles of materiality, politics and gover- 
nance cultures (Decuypere \& Landri, 2020; Gorur, 2011; Williamson, 2019). A related and established line of enquiry in education policy research often follows heterogeneous actors and ideas across different contexts, mapping their trajectory between fields and examining how forms of knowledge are "signified" as they move and consolidate (Ball, 2016; Savage, 2020). In the same vein, several authors have examined social practices and events where techno-scientific concepts, and their authoritative human advocates, tend to converge and can be observed (Gulson \& Witzenberger, 2020; McCann \& Ward, 2012; Perrotta, Bailey, Ryder, Haggis-Burridge, \& Persico, 2019). Taken together, assemblage studies are producing rich accounts of distributed agency, beginning to displace deterministic narratives where a traditional understanding of cause and effect lies at the centre of theorisation and empirical enquiry. Tracing the theoretical influences of these contributions takes us to a diverse pool of ideas not always aligned with each other. Indeed, some disagreements can be fierce and are largely unresolved (Bloor, 1999; Latour, 1999). Nonetheless, the studies mentioned previously are often quite pragmatic and open to cross-contamination when it comes to theoretical influences, and this essay is much in the same spirit. Deleuze is often credited with introducing the concept of assemblage to describe the multi-layered nature of social -and indeed natural- phenomena (Deleuze, 1988). Other influences can be found in Foucault's writings, especially in his analysis of discursive/behavioural/material "dispositifs" (Foucault, 1978), and of course in Bruno Latour's emphasis on networked entanglements of humans and non-humans (Latour, 2005).

Another important inspiration is the post-Kantian strand of philosophy that tried to reconcile an interest in materiality with an anti-essentialist and "flat" ontology whereby everything that exists has the same right to "stake its claim in the world" (Harman, 2008, p. 371). This ontology underscores a view of reality as an emergent process, whereby assemblages rise and fall, held together by relations between their tangible and discursive properties.

The aim in this essay is to identify one the "first principles" of assemblage studies in education. I argue that such principle has to do with the thesis of underdetermination, which posits that the relationship between causes and effects is, indeed, underdetermined by a plurality of social and cultural factors continuously bound and unbound by relations of dependency, alliance and conflict. Put more simply, underdetermination means that we can never be completely certain, because the number of immeasurable and irregular events about any given phenomenon will always outweigh those that can be counted and classified. Thus, alternative accounts -often of a sociological and cultural nature- become possible and linear causal linkages can be reframed in more heterogeneous terms as associations or tensions between forces. At the risk of overgeneralising, I argue here that the underdetermination thesis lies at the heart of all arguments mounted against objectivist science and technological determinism.

Indeed, this concept played a crucial role in the development of the sociology of knowledge as a discipline, and in particular the "strong programme" advocated by a group of seminal scholars during the 1980s and early 1990s (Bloor, 1998; Collins \& Evans, 2002; Mackenzie \& Wajcman, 1999). These authors assertively tried to move the social study of science away from the weak review of methodological aberrations (e.g. the debunking of 
pseudoscience), and towards a more ambitious -and compelling-critique of the sociocultural conditions of possibility that underdetermine knowledge. Indirectly associated with this strong programme, and without doubt operating in the same philosophical tradition, Andrew Feenberg is one of the most prominent contemporary thinkers who helped further theorize the notion of underdetermination. As he puts it:

The constructivist concept of underdetermination explains the conditions of possibility of successful public interventions into the design of the techno-system. This concept describes the contingency of technical developments and releases the analysis of the design process from technocratic assumptions.

(Feenberg, 2017, p. 199)

In his work on technology, Feenberg explored the limits of positivism and social rationality by drawing on seminal ideas from sociology and cultural theory. His view, which underpins much of what this article has to say about educational technology, is that technological design is often sustained by a myth of pure rationality and progress, when in fact it is a function of capitalism, regularly framed in the dominant discourse as a natural form of social organisation, rather than an ideology (Feenberg, 2010). However, critiquing technology because of its ideological bias does not entail veering towards non-rational explanations. Feenberg argues that critique must instead begin with an acknowledgement of the compelling internal consistency of rational systems (e.g. technological progress and the capitalist market). Therefore, the task is not to expose these systems as non-rational but to show that their rationalism is biased and discriminatory, because it benefits some groups at the expense of others. Following this broad critical project, this essay explores underdetermination as a means to interrogate the (biased) social rationality of educational technology research. It achieves this by identifying the underlying proposition and the postulates of underdetermination, and then discussing their broad applicability to contemporary issues of datafication and techno-surveillance in education.

\section{THE PROPOSITION: PAY ATTENTION TO RELATIONS}

The analysis of relations is often used to support the underdetermination thesis: alliances, conflicts and feuds, strategies of persuasion or even seduction, negotiated or imposed epistemic authority, reputation and status, and so forth (Venturini, Jensen, \& Latour, 2015). In most cases, the aim is to develop a critical perspective through an "emic" (ethnomethodological) understanding, that is, an in-depth engagement with the value-laden epistemic landscapes inhabited by highly specialised experts, policy makers, thought leaders, power brokers, knowledge translators and a multitude of assorted intermediaries (including non-human ones). This work seeks to illuminate the intermingling of messy meaningmaking and structured knowledge within and across assemblages, with a focus on situated practices and institutional modi operandi.

The analysis of relations is, however, a broad and ill-defined endeavour that can take different forms sometimes in fierce disagreement with each other. Hence, various influences 
may take centre stage or shift in the background depending on disciplinary allegiances and theoretical leanings. Some accounts prioritise gender relations within historic patterns of bodily and social oppression (Haraway, 1991). Others have used a Foucauldian perspective to examine the subtle ways in which power shapes sociotechnical relations (Barry, 2001; Introna, 2016). A fascinating body of work took instead an "ontological" turn by arguing that the very nature of existence is the result of practical enactments (Law \& Mol, 2002; Mol, 2002). The latter position is noteworthy for its uncompromising commitment to social constructivism: reality, according to a "flat" ontology, is never something that precedes social practice but is always a consequence of it. This means that social actors bring into existence various versions of a certain phenomenon, through context-dependent processes of enactment that generate multiple, not necessarily coherent, objects. This position is contrasted by a "traditional ontology that posits an underlying and coherent unity beneath circumstantial variations." (Lynch, 2013, p. 458)

Despite their differences, one constant can be detected throughout these discussions: the idea that relations and tensions operate -directly or indirectly- to tease some order or stability out of the often-controversial uncertainty of social reality. Through the description of relations of ordering and stabilisation -what Annamarie Mol called ontological politics (Mol, 1999)- scholars committed to underdetermination have developed detailed case studies of how technologies and forms of specialist knowledge are continuously renegotiated through conflicts and alliances. The idea of relation is therefore of crucial importance. It serves a very specific goal that needs to be made more explicit in the context of a theoretical discussion: to upset linear causal explanations and replace them with relational accounts that document the plural, uncertain and messy nature of techno-scientific knowledge. It is, however, a descriptive notion. In the language of Euclidean geometry, it is a proposition: something which has do be done ("describe the relations!"), as opposed to something which has to be proved (Mueller, 1969). Relational analyses abound in Science and Technology Studies (STS), infrastructure studies, Post-Deleuzian and post-Foucauldian studies of technology and so forth -but the description and cataloguing of relations may sometimes distract from the underpinning theoretical rationale: why do we describe relations? The answer is, indeed, underdetermination. We are drawn to relational analyses because we seek to prove the role of culture and society in providing alternative accounts, and because we are suspicious of the enduring claims of truth, objectivity and impartiality made by scientists and engineers, or on behalf of them by a plethora of interested and biased parties. I believe it is important to state this unequivocally but, in doing so, we raise another theoretical question: if relationality is the empirical proposition of underdetermination, what are the postulates? 


\section{THE POSTULATES: UNAVOIDABLE UNCERTAINTY AND PRAGMATISM}

\subsection{The Uncertain Relationship Between Evidence and Experience}

The first postulate of underdetermination is that the role of empirical evidence in forming and changing our experience is limited. In the age of rampant climate science denialism this postulate may not seem in need of much proof, but there remains in the mainstream cultural discourse a staunch rhetorical commitment to evidence-based argumentation as the only acceptable framework for social action, despite mounting evidence to the contrary. The "twist" here is that the uncertain relationship between evidence and rationality concerns lay people as much as scientists and engineers who, in their own distinctive ways, are swayed by sociocultural interests and dynamics, as Kuhn and many sociologists of knowledge after him argued (Collins \& Evans, 2002).

The suggestion -or provocation- that there may be an undercurrent of intractable uncertainty running through all versions of epistemology (expert and naïve alike), was articulated as a logical argument in the philosophy of Willard Van Orman Quine, who suggested that our beliefs are suspended in a thick web of influences, which comes into contact with experience only at the periphery. As such, belief systems can be thought of as interconnected organisms in a pond. When something (evidence and experience) touches the edge of the water, the ripples are propagated through the linkages in ways that may cause some changes in the system, but...

The total field is so underdetermined by its boundary conditions that there is much latitude of choice as to what statements to re-evaluate in the light of any single contrary experience. No particular experiences are linked with any particular statements in the interior of the field, except indirectly through considerations of equilibrium affecting the field as a whole.

(Quine, 1951, p. 42-43)

Critics (e.g. Laudan, 1990) argued that such views dangerously drift towards relativism, and proposed a distinction between mild forms of underdetermination which amount to accepting the possibility of confounding variables and non-meaningful correlations, and more radical forms, such as the thesis of complete equivalence between theories (Kukla, 1996) which should be avoided because they entail that truth and evidence no longer have any bearing on how we conduct ourselves in the world.

The relationship between experience and evidence is a complex topic, and much of the associated debate too philosophically broad for this essay. The position preferred here is that experience and worldly evidence are in a dialectic relationship where they constitute each other continuously in the context of a social milieu (Lukács, 2001). The material and historical conditions of knowledge are therefore real, but human experience is not simply a recipient for them. Instead, people need to construct their experience by contrasting it with history and culture and questioning their own place in both. This explains why something can be true, and not yet real for many people who struggle to relate their experiences with 
the social forces that structure them. Climate change is true, but it is unreal for many who are unwilling or unable to place this truth in a broader historical crisis of capitalism, which will lead them to questioning their own way of life. The more experience "grasps hold of the living contradictions of life and society, then the greater and more profound the realism will be." (Lukács, 2001, p. 1044)

These philosophical discussions have raged for centuries and it is beyond the scope of this essay to delve into them. The main reason for bringing elements of this debate to bear is to show how the seeds of doubt about the universal validity of linear empiricism, planted by multiple classic and modern thinkers, have led to a search for alternatives in the social sciences, moved by a desire to tell "other stories" about knowledge and the world in general. These stories are no longer interested in the purity of truth, but seek to cast a light on more mundane questions of sociocultural import: how can something be true and simultaneously not real for millions of people? Who does knowledge belong to? Who benefits from it? Who is excluded? How does knowledge actually come together through linguistic conventions, forms of situated practices and embodiments, i.e. "forms of life" (Wittgenstein, 2009)?

The key point, to reiterate, is that underdetermination is the principle that justifies the need to bring non-cognitive, social factors to bear when explaining the work that is done through science and technology. The entire STS field came into being when multiple social scientists agreed that knowledge cannot be conceptualised as an abstract pursuit of truth undertaken by disembodied minds outside of history and culture. Bowker and Star aptly describe this shift as the abandonment of the "Herculean, Sisyphean task" (Bowker \& Star, 1999, p. 13) of arbitrating between opposing epistemologies, and cite the eminent sociologist Howard S. Becker to illustrate their point:

Epistemology has been a ... negative experience, mostly devoted to saying what you shouldn't do if you want your activity to merit the title of science, and to keeping unworthy pretenders from successfully appropriating it. The sociology of science, the empirical descendent of epistemology, gives up trying to decide what should and shouldn't count as science, and tells what people who claim to be doing science do.

(Becker, 1996, p. 53)

However, this shift has resulted in a growing, not always deliberate, indifference among many social scientists for the problem of causality, which creates a political impasse. I will return to this problem in the concluding discussion. For now, let us continue with the review of the second postulate of underdetermination.

\section{2 \#2 Pragmatism: Things Which Are Treated as Real Are Real in Their Consequences}

In his influential work, Bruno Latour critiqued in compelling terms the non-neutral tendencies of scientific methods where all human and non-human intermediaries, including calculative devices and mathematical concepts, play a constitutive role by translating and materialising knowledge (Latour, 1988). The recent interest in "big data" reinvigorated this 
argument when it became clear that in the realm of digital quantities and algorithms the epistemic edifice of statistics does not only provide calculative affordances and a specialist terminology, but is also constitutive of the calculative operation (Boullier, 2018, p. 6).

This position foregrounds the importance of "performativity" in the dynamics of knowledge production. Drawing on pragmatist theories of language (Austin, 1975), performativity posits that the instruments for the measurement and the classification of the world are actively implicated in its instantiation. Performativity has been used to describe how neoliberal market conditions are not only the result of structural factors, but also the product of a loose apparatus of economic theory, research and algorithmic financial innovations which actively intervenes in the enactment of a particular economic reality: markets are not natural, they are made (Mackenzie, Muniesa, \& Siu, 2007). In educational assemblage studies, the notion of performativity helped describe the political economies of higher education, with its retinue of market-making performances: quantification practices, private-public alliances, benchmarking frameworks and so forth (Komljenovic \& Robertson, 2016).

Performativity is therefore the second postulate of underdetermination. Its main pragmatist assertions are that "things perceived as real are real in their consequences." (Bowker \& Star, 1999, p. 13), and that the entire edifice of scientific and technical methodology, with its manifold infrastructures for measuring, comparing, ranking, counting and controlling social life, changes the world by acting upon it.

The notion of performativity has been used to interrogate the "social life" of learning analytics, understood as an emerging sociotechnical assemblage in education (Perrotta \& Williamson, 2018). Learning analytics is a growing field of scholarship and commercial activity where computational methods are used to address research questions mostly concerned with the psychology of learning or for administrative purposes, i.e. to support strategic institutional goals in higher education like student retention. The success of this field, illustrated by academic citations, funded research, large investments in infrastructure and a growing marketplace (Dawson, Gašević, Siemens, \& Joksimovic, 2014), can be read in an uncritical and deterministic manner as the result of inevitable technological developments, which rendered "traditional" approaches to educational research and administration obsolete, and thus unable to deal with the data deluge of the early 21 st century. However, the domain of learning analytics is far from being a collection of techniques or an exact science. In fact, learning analytics is very ideological in its faith that digital data will reveal insights which would remain otherwise inaccessible. This distinct ideology underdetermines, alongside other sociocultural and economic factors, the very rational work that is done through learning analytics, carried out by a growing community of well-meaning scholars and administrators. It is therefore possible to scrutinise the tendency in the LA field to position itself as objective science, without threatening its internal rationality or the rigour of the research done in its name.

Paraphrasing Howard Becker (see previous section): once an underdetermination lens is adopted, the task is no longer to decide what parts of learning analytics should count as proper science and what shouldn't, but to tell alternative stories that explain a) what people who claim to be doing learning analytics actually do in their social lives; and b) how the 
methods of learning analytics are always performative to a higher or lesser degree. This is an important theoretical shift from knowledge per se to the social conditions where knowledge is (re)produced, with its cultural practices and ideologies, and from the boundary region of empirical evidence, to the web of underdetermining influences that lie beneath.

\subsection{What is good about UD?}

The greatest strength of underdetermination is that it gives a voice to marginalised perspectives in its accounts of how knowledge is (relationally) produced and negotiated. It is no coincidence that some of the most exciting accounts of underdetermination can be found in feminist techno-science (Wajcman, 2004). This shows that describing unorthodox, neglected relations within and across assemblages can be a critical enactment in its own right, despite a tendency to eschew traditional "human politics", often highlighted by critics of STS and Actor Network Theory (ANT) (e.g., most recently, Couldry, 2020). Another related strength of underdetermination is that it makes "thinking otherwise" possible. Take, for instance, the contemporary infrastructures of datafication and surveillance in education. Critical research in education technology treats these phenomena as an expression of ideological and commercial influences in education, but on closer inspection we can detect two alternative critical readings. In the first one, the contemporary ed-tech project is the result of a coordinated political design, the only ethical response to which can be radical and all-out resistance. The second reading conceptualises ed-tech as a disordered assemblage; a certainly rational, but not terribly consistent agglomeration of quantification, prediction and surveillance infrastructures that provide "oligoptic views of the world: views from certain vantage points using particular tools, rather than an all-seeing, infallible God's eye view." (Kitchin, 2014, p. 4). In other words, education technology (with all its problems) can either be viewed as a unitary political-economic project, or as a sociotechnical grid open to fragmentation, with human and non-human actors mobilising technologies for surveilling, measuring and disciplining, often without communication and with no interfacing: inspection agencies, national and international assessment frameworks, classification and ranking systems, computational methods, interoperable databases and a growing marketplace of proprietary digital platforms. This imperfect panopticon is not the result of clear-cut malicious intentions but is instead underdetermined by multiple sociotechnical influences. Underdetermination, in other words, tells us that the development of educational technology infrastructures is a fractured and iterative accumulation of relational enactments, which can be "reverse engineered" by foregrounding the work involved in their making. This is what Bowker and Star (Bowker and Star, p. 34) call "infrastructural inversion". By engaging with underdetermination, research on educational technology can move towards a new form of public utility, beyond the embarrassing stigma of existing solely to validate a multibillion industry. On the one hand, it can be a mirror held up to that industry, raising questions about networks of interests and manufactured objectivity. On the other, it can begin to expand the "infrastructural imagination", in order to redefine notions of design and usage in a more inclusive and socially just way (Gray, Gerlitz, \& Bounegru, 2018). 


\subsection{The Bad: Weak Politics and the "Soup" of Emergent Causality}

When social researchers turned to social constructivism and heterogeneity, they probably did not anticipate that these ideas could be hijacked to serve dubious agendas. The already mentioned philosophical critique of underdetermination highlighted the dangers of relativism. However, that was a relatively tame philosophical argument concerned with "proper science". What we are observing in the current historical moment is something much more political and altogether unpleasant, as notions of pluralism, structural uncertainty and localised knowledge are appropriated by authoritarian discourses. This argument has been made recently, and compellingly, in the context of media and surveillance studies (Andrejevic, 2020; Couldry, 2020), and it is extremely relevant to our work as education technology researchers. Against a background of aggressive datafication, the rise of obscure infrastructures of prediction, and a shift towards illiberal worldviews, the need for political action is urgent (Zuboff, 2019).

Unfortunately, it is hard to undertake or even imagine any kind of political action without explanations that connect antecedents (e.g. structural inequalities) and consequences (e.g. oppression). There are marked differences in the commitment to underdetermination amongst all the authors cited in this essay, but there remains across most of them a generalised scepticism towards objectivist explanations. However, there are human and moral dimensions to objectivist explanations that perhaps we should not so quickly disavow.

Explanations are one form of narrative that play an important role in our lives: we tell ourselves stories that link past and present, cause and effect, often in highly contested contexts (consider the narrative struggle around global warming). The drive for control and understanding manifested in these explanatory stories is one of our most compelling motivations for narration. Narratives provide us with the sense that we can understand our world and, crucially, that this understanding provides us with some form of control.

(Andrejevic, 2020, p. 34)

A too radical insistence on underdetermination and relationality disables, argues Andrejevic, this narrative form of causality, because consequences can no longer be linked to antecedents, and otherwise linear and tractable connections are replaced by entanglements of factors and heterogenous influences, about which we can do little. The elision of narrative causality, continues Andrejevic, pushes "perhaps unwittingly, in the direction of total information capture" (Andrejevic, 2020, p35). Notions of emergent causality provide, in other words, an implicit rationale for pre-emptive surveillance: since we cannot hold any certain knowledge about the world and the intentions of actors within it, then it is justified to offload onto machines the task of nudging us through unexplainable assemblages. This offloading entails an "operational bias" (Andrejevic, 2020, p. 95) that seeks to replace explanation with correlation, in order to act pre-emptively without the need for human judgement or even comprehension. Similar points are beginning to be raised in critical examinations of algorithmic logics in education (Knox, Williamson, \& Bayne, 2020). 


\section{CONCLUSION: REDISCOVERING ANTAGONISM}

This essay examined underdetermination as a first principle in a research strand, broadly described as "assemblage studies" in education, which focuses on the relations between technology, education, policy and the broader society. The article's goal is to encourage further theoretical discussion. In this sense, the distinction between the proposition of underdetermination (relationality) and its postulates (epistemological/ontological uncertainty and pragmatism) can bring a degree of clarity and precision to the debate. The essay also attempted a balanced examination of the strengths and weaknesses of underdetermination and, in particular, it drew attention to the risks of an overcommitment to pluralist epistemologies and flat ontologies, that is, a weakening of political action and the implicit justification of logics of surveillance and datafication. In this conclusion, I want to explore some ways forward, avoiding undue deference to one paradigm or another. My understanding of assemblage studies is as a diverse gathering of ideas not reducible to, say, actor-network theory or the sociology of scientific knowledge, and while there are plenty of disagreements, all approaches covered here share an interest in the social construction of the world. They also share a tendency to prioritise description over explanation and, as noted above, are prone to political impasse. Therefore, what other ideas can we mobilise to address these criticalities without losing the empirical richness and the valorisation of heterogeneity? Some interesting answers come once more from recent discussions in media and surveillance studies. Andrejevic, for example, turns to the Lacanian psychoanalysis of Zupančič (2017), for whom "the subject is not simply an object among many objects, it is also the form of existence of the contradiction, antagonism at work in the very existence of objects as objects. (2017, p.122). In doing so, Andrejevic seeks to reintroduce an interest for the dimension of intersubjective conflict, which plays a crucial role in shaping our understanding of narrative causality. In the same vein, Couldry warns us against the pitfalls of a flat ontology, where all entities can stake a claim to existence and morality becomes a grey area. Assemblage studies should, in this sense, engage with the "personal and moral tensions" (Couldry, 2020, p. 1143) that underlie the reproduction of the social order, analysing the impacts of those tensions on people's lives, and detecting the underpinning capitalist logics that benefit some at the expense of others (Boltanski, 2011; Elias, 1991; Postone, 1993).

For both Andrejevic and Couldry, the chief suggestion is not so much about a new form of naïve humanism that gives people a privileged status among other "actants" in an assemblage, but about rediscovering the dialectic nature of ontological politics, where multiple antagonistic impacts of technology stand in contradiction (for a similar position see also Fuchs, 2020). Antagonism means that, within and across assemblages, there are always winners and losers, exploited and exploiters, those who are visible and those who are not. These categories apply to humans and non-humans alike but, perhaps, we have a moral duty to address their disrupting consequences on the lived experiences of the former.

\section{REFERENCES}

Andrejevic, M. (2020). Automated media. Routledge. https://doi.org/10.4324/9780429242595 
Austin, J. L. (1975). How to do things with words (2nd ed.). Clarendon Press. https://doi.org/10.1093/ acprof:oso/9780198245537.001.0001

Ball, S. J. (2016). Following policy: networks, network ethnography and education policy mobilities. Journal of Education Policy, 31(5), 549-566. https://doi.org/10.1080/02680939.2015.1122232

Barry, A. (2001). Political machines: Governing a technological society. A\&C Black.

Becker, H. S. (1996). The epistemology of qualitative research. In R. Jessor, A. Colby, \& R. A. Shweder (Eds.), Ethnography and human development: Context and meaning in social inquiry (pp. 5371). University of Chicago Press.

Bloor, D. (1998). Sociology of knowledge. Routledge Encyclopedia of Philosophy. Rouledge. Retrieved from https://doi.org/10.4324/9780415249126-R033-1 https://doi.org/10.4324/ 9780415249126-R033-1

Bloor, D. (1999). Anti-latour. Studies in History and Philosophy of Science Part A, 30(1), 38-45. https://doi.org/10.1016/S0039-3681(98)00038-7

Boltanski, L. (2011). On Critique: A Sociology of Emancipation. Verso Books.

Boullier, D. (2018). Médialab stories: How to align actor network theory and digital methods. Big Data \& Society, 5(2). https://doi.org/10.1177/2053951718816722

Bowker, G. C., \& Star, S. L. (1999). Sorting things out : classification and its consequences. MIT Press. https://doi.org/10.7551/mitpress/6352.001.0001

Collins, H. M., \& Evans, R. (2002). The Third Wave of Science Studies: Studies of Expertise and Experience. Social Studies of Science, 32(2), 235-296. https://doi.org/10.1177/ 0306312702032002003

Couldry, N. (2020). Recovering critique in an age of datafication. New Media \& Society, 22(7), 1135-1151. https://doi.org/10.1177/1461444820912536

Dawson, S., Gašević, D., Siemens, G., \& Joksimovic, S. (2014). Current state and future trends: a citation network analysis of the learning analytics field. Proceedings of the Fourth International Conference on Learning Analytics And Knowledge. https://doi.org/10.1145/2567574.2567585

Decuypere, M., \& Landri, P. (2020). Governing by visual shapes: university rankings, digital education platforms and cosmologies of higher education. Critical Studies in Education, 1-17. https://doi.org/10.1080/17508487.2020.1720760

Deleuze, G. (1988). A thousand plateaus : capitalism and schizophrenia. Athlone Press.

Elias, N. (1991). The Society of Individuals. Hutchinson.

Feenberg, A. (2010). Marxism and the critique of social rationality: from surplus value to the politics of technology. Cambridge Journal of Economics, 34(1), 37-49. https://doi.org/10.1093/cje/ bep006

Feenberg, A. (2017). Technosystem : The Social Life of Reason. Harvard University Press. https:// doi.org/10.4159/9780674982109

Foucault, M. (1978). The history of sexuality. Pantheon Books.

Fuchs, C. (2020). Communication and Capitalism A Critical Theory (Vol. 15). University of Westminster Press. https://doi.org/10.2307/j.ctv12fw7t5

Gorur, R. (2011). Policy as Assemblage. European Educational Research Journal, 10(4), 611-622. https://doi.org/10.2304/eerj.2011.10.4.611

Gray, J., Gerlitz, C., \& Bounegru, L. (2018). Data infrastructure literacy. Big Data \& Society, 5(2). https://doi.org/10.1177/2053951718786316

Gulson, K. N., \& Witzenberger, K. (2020). Repackaging authority: artificial intelligence, automated governance and education trade shows. Journal of Education Policy, 1-16. https://doi.org/ $10.1080 / 02680939.2020 .1785552$

Haraway, D. J. (1991). Simians, cyborgs, and women: the reinvention of nature. Routledge.

Harman, G. (2008). DeLanda's ontology: assemblage and realism. Continental Philosophy Review, 
41(3), 367-383. https://doi.org/10.1007/s11007-008-9084-7

Introna, L. D. (2016). Algorithms, Governance, and Governmentality. Science, Technology, \& Human Values, 41(1), 17-49. https://doi.org/10.1177/0162243915587360

Jacobsen, W. C., \& Forste, R. (2011). The Wired Generation: Academic and Social Outcomes of Electronic Media Use Among University Students. Cyberpsychology, Behavior, and Social Networking, 14(5), 275-280. https://doi.org/10.1089/cyber.2010.0135

Kitchin, R. (2014). Big Data, new epistemologies and paradigm shifts. Big Data and Society, 1(1). https://doi.org/10.1177/2053951714528481

Knox, J., Williamson, B., \& Bayne, S. (2020). Machine behaviourism: future visions of 'learnification' and 'datafication' across humans and digital technologies. Learning, Media and Technology, 45(1), 31-45. https://doi.org/10.1080/17439884.2019.1623251

Komljenovic, J., \& Robertson, S. L. (2016). The dynamics of 'market-making' in higher education. Journal of Education Policy, 31(5), 622-636. https://doi.org/10.1080/02680939.2016.1157732

Kukla, A. (1996). Does every theory have empirically equivalent rivals? Erkenntnis, 44(2), 137-166. https://doi.org/10.1007/bf00166499

Latour, B. (1988). The pasteurization of France. Cambridge, Mass: Harvard University Press. https:// doi.org/10.1016/S0039-3681(98

Latour, B. (1999). For David Bloor... and beyond: A reply to David Bloor's' anti-Latour'. Studies in history and philosophy of science, 30, 113-130.

Latour, B. (2005). Reassembling the social an introduction to actor-network-theory. Oxford University Press.

Laudan, L. (1990). Science and relativism - some key controversies in the philosophy of science. The University of Chicago Press. https://doi.org/10.7208/chicago/9780226219332.001.0001

Law, J., \& Mol, A. (2002). Complexities : social studies of knowledge practices. Duke University Press. https://doi.org/10.1215/9780822383550

Luckin, R. (2010). Re-designing learning contexts : technology-rich, learner-centred ecologies. Routledge.

Lukács, G. (2001). Realism in the Balance. In V. Leitch (Ed.), The Norton Anthology of Theory and Criticism (pp. 1033-1058). W.W. Norton \& Company.

Lynch, M. (2013). Ontography: Investigating the production of things, deflating ontology. Social Studies of Science, 43(3), 444-462. https://doi.org/10.1177/0306312713475925

Mackenzie, D., Muniesa, F., \& Siu, L. (2007). Do economists make markets? : on the performativity of economics. Princeton University Press. https://doi.org/10.1515/9780691214665

Mackenzie, D., \& Wajcman, J. (1999). The social shaping of technology. Open university press.

McCann, E., \& Ward, K. (2012). Policy Assemblages, Mobilities and Mutations: Toward a Multidisciplinary Conversation. Political Studies Review, 10(3), 325-332. https://doi.org/10.1111/ j.1478-9302.2012.00276.x

Mol, A. (1999). Ontological Politics. A Word and Some Questions. The Sociological Review, 47(1_suppl), 74-89. https://doi.org/10.1111/j.1467-954x.1999.tb03483.x

Mol, A. (2002). The body multiple : ontology in medical practice. Durham: Duke University Press.

Mueller, I. (1969). Euclid's Elements and the Axiomatic Method. The British Journal for the Philosophy of Science, 20(4), 289-309. https://doi.org/10.1093/bjps/20.4.289

Perrotta, C., Bailey, C., Ryder, J., Haggis-Burridge, M., \& Persico, D. (2019). Games as (Not) Culture: A Critical Policy Analysis of the Economic Agenda of Horizon 2020. Games and Culture, 15(8), 902-922. https://doi.org/10.1177/1555412019853899

Perrotta, C., \& Williamson, B. (2018). The social life of Learning Analytics: cluster analysis and the 'performance' of algorithmic education. Learning, Media and Technology, 43(1), 3-16.

Postone, M. (1993). Time Labor and Social Domination. Cambridge University Press. https:// 
doi.org/10.1017/CBO9780511570926

Quine, W. V. (1951). Main Trends in Recent Philosophy: Two Dogmas of Empiricism. The Philosophical Review, 60(1), 20-43. https://doi.org/10.2307/2181906

Savage, G. C. (2020). What is policy assemblage? Territory, Politics, Governance, 8(3), 319-335. https://doi.org/10.1080/21622671.2018.1559760

Selwyn, N. (2010). Looking beyond learning: notes towards the critical study of educational technology. Journal of Computer Assisted Learning, 26(1), 65-73. https://doi.org/10.1111/ j.1365-2729.2009.00338.x

Venturini, T., Jensen, P., \& Latour, B. (2015). Fill in the Gap: A New Alliance for Social and Natural Sciences. Journal of Artificial Societies and Social Simulation, 18(2), 1-4. https://doi.org/ 10.18564 /jasss.2729

Wajcman, J. (2004). TechnoFeminis. Polity Press.

Williamson, B. (2019). Psychodata: disassembling the psychological, economic, and statistical infrastructure of 'social-emotional learning. Journal of Education Policy, 36, 129-154. https://doi.org/10.1080/02680939.2019.1672895

Wittgenstein, L. (2009). Philosophical investigations (P. M. S. Hacker \& J. Schulte, Eds.). WileyBlackwell.

Zhao, Y., \& Frank, K. A. (2003). Factors Affecting Technology Uses in Schools: An Ecological Perspective. American Educational Research Journal, 40(4), 807-840. https://doi.org/10.3102/ 00028312040004807

Zuboff, S. (2019). The Age of Surveillance Capitalism: The Fight for a Human Future at the New Frontier of Powe. Profile Books.

Zupančič, A. (2017). What is sex? The MIT Press. https://doi.org/10.7551/mitpress/11367.001.0001 